\title{
Influence Analysis of Persistent Joint on Single-Hole Blasting Damage of Rock Mass
}

\author{
Bing Xie ${ }^{1}$, Yanqiang Du ${ }^{1, *}$, Hongling Zhao ${ }^{1}$, Zhigang Du${ }^{1}$ and Brian Mullarney ${ }^{2}$ \\ ${ }^{1}$ Civil Engineering Department, Luoyang Institute of Science and Technology, Luoyang, 471023, Henan, China \\ ${ }^{2}$ School of Engineering \& Materials Research Institute, Athlone Institute of Technology, Dublin Road, Athlone Co. Westmeath, Ireland
}

Received 10 January 2020; Accepted 22 May 2020

\begin{abstract}
It is difficult to be measure and analyze the blasting damage of rock masses containing persistent joint. A field test was conducted to determine the distribution range of blasting damage zone in intact rock mass for investigating the macroscopic characteristics of blasting damage of rock masses containing persistent joint and effectively predicting the damage scope. The effectiveness of the numerical calculation was verified by combining the calculation of blast load using finite element ANSYS/AUTODYN software and the calculation of blasting damage zone of rock masses using discrete element UDEC software. Typical numerical calculation models of persistent joint passing through the upper, middle, and lower parts of the blast hole were constructed to investigate the distribution laws of blasting damage zone in rock masses under the joint dip angles of $0^{\circ}, 15^{\circ}, 30^{\circ}, 45^{\circ}, 60^{\circ}$, and $75^{\circ}$. Results indicate that the distribution pattern of blasting damage zone is significantly affected by existence of persistent joint. The maximum blasting damage width under a small joint dip angle is approximately 1.8 times that under non-joint condition. The maximum blasting damage depth under a large joint dip angle is approximately 2.3 times that under non-joint condition. Under the special circumstance in which the joint with the dip angle of $90^{\circ}$, the joint nearly has no influence on blasting damage width but remarkable influence on blasting damage depth.
\end{abstract}

Keywords: Persistent joint; Single-hole blasting; Rock damage; Numerical calculation

\section{Introduction}

In the tunnel construction process of hydraulic and geotechnical engineering, blasting is still a widely applied rock breaking method. In blasting off rock masses within the excavation scope, explosives will certainly damage the reserved rock masses. Accordingly, the mechanical properties and bearing capacity and stability of these rock masses will be degraded. Moreover, the existence of joints in rock masses, especially persistent joint, will result in unbalanced blasting energy distribution, seriously obstruct propagation of blasting stress waves, aggravate attenuation of blasting energy, and cause complicated distribution of rock blasting damage zone. Therefore, the prediction formulas of blasting damage width and depth of rock masses containing persistent joint were proposed to acquire the macroscopic blasting damage characteristics of rock masses containing persistent joint and accurately predict the scope of blasting damage.

Among the traditional studies on scope of blasting damage of rock masses, most domestic and foreign scholars have regarded rock masses as a continuum and studied constitutive model of blasting damage $[1,2]$ and blasting damage characteristics and distribution in rock masses through the defined damage variables $[3,4]$. However, they have neglected the influence of joints on blasting damage of rock masses, which results in differences from practical engineering. Even if the influence of joints on blasting damage of rock masses is considered, the rock masses are still regarded as a continuum for analysis after joints are

\footnotetext{
*E-mail address: rs425@126.com

ISSN: $1791-2377$ @ 2020 School of Science, IHU. All rights reserved.

doi:10.25103/jestr.133.06
}

considered an influencing factor of strength degradation of rock masses [5]. For common blasting with hole depth ranging from $1 \mathrm{~m}$ to $3 \mathrm{~m}$ in tunnel blasting engineering and evident persistent joint existing in the scope of the blast holes, errors will unavoidably be generated if the rock masses are regarded as a continuum in the research of blasting damage problem of rock masses.

On this basis, the influence of joints on blasting damage of rock masses remains to be further investigated in the blasting process of rock masses containing persistent joint. The single-hole blasting damage of rock masses containing persistent joint will be investigated in this study to reveal the influence laws of persistent joint on scope of blasting damage of rock masses and provide a reference for the design and construction of blasting engineering.

\section{State of the art}

Blasting damage problem of rock masses has been attracting considerable attention from engineering technicians and research scholars in various countries. However, related works on blasting damage of jointed rock masses are limited and are still in a preliminary stage due to the complexity of engineering rock masses and uncertainties existing in structural planes, such as joints and cracks. To date, domestic and foreign scholars have used testing means and numerical calculation methods to investigate blasting damage and fracture of engineering rock masses. Some calculation methods applicable to engineering design have also been introduced. These works have mainly focused on determining the theoretical model of dynamic damage and fracture of rock masses, testing of blasting damage scope, 
and finite element numerical calculation of such damage. For instance, Pramanik [6] used smoothed particle hydrodynamics (SPH) method to study the dynamic failure mechanism of brittle surrounding rocks under blasting stress waves and high-pressure gas expansion and corrected Grady-Kip tensile yield damage model and Drucker-Prager shear failure model. Dehghan [7] conducted an accurate single-hole blasting test on granite specimens and combined finite element calculation to study the stress wave-induced crack propagation modes in rocks. Bendezu [8] proposed a numerical analysis method based on finite element method to simulate crack propagation in hard rocks caused by blasting. Liu [9] deemed that non-persistently jointed rock masses were composite geological materials containing macroscopic defects, such as joints and cracks, and microscopic defects, such as microcracks and microholes. On this basis, Liu [9] constructed a constitutive model for dynamic damage of non-persistently jointed rock masses in consideration of macroscopic and microscopic defects. Most of the above-mentioned works have assumed rock masses as a continuous medium and conducted damage and fracture analysis under dynamic load, but they have ignored the influence of joints on the damage zone under the action of blasting stress wave, However, Liu [9] considered the influence of joints and regarded jointed rock masses as a continuum of composite material while ignoring the influence of joints on blasting damage from a macroscopic angle.

Accurate test and analysis of blasting damage scope of rock masses is quite difficult. For example, Hamdi [10] introduced an experimental method based on digital image technology to evaluate internal microcracks in rocks and quantify rock damages. Maxwell [11] investigated the characterization problem of blasting damage zone of rock masses using the seismic topographical technique. Verma [12] took cores from engineering rock masses for a test, calculated core recovery and rock quality designation, and acquired the damage status of rock masses by comparing the calculated results to assess the influence of blasting on surrounding rocks. Navarro [13] proposed using drilling indexes to measure blasting-induced damage of residual rock masses. The aforementioned studies have tested the blasting damage scope of rock masses by advanced means and methods. However, few of them have mentioned prediction and calculation of blasting damage scope of rock masses under the existence of persistent joint.

Yilmaz [14] studied the blasting damage scope of rock masses through the numerical calculation method and used 3D finite-difference numerical simulation method to explore the mechanical behaviors of rock masses under blast load and the effects of loading rate and anisotropic high ground stress on blasting performance and damage zone under different blasting and site conditions. García [15] combined the theory of rock blasting of Langefors and the existing experimental data to propose a new model for predicting blasting damage degree of rock masses in consideration of the influence of reduced internal energy when gas expanded toward the well wall. Jayasinghe [16] raised an SPH and finite element coupling model, which was used to study the scope and fracture mode of blasting zone of rocks. On this basis, he investigated the influences of factors, such as high ground stress, on the evolution of blasting damage. Most of the above-mentioned works have used finite element method to study blasting damage zone of rock masses, which are considered a continuum. However, they have ignored the fact that the appearance of joints will result in displacement and stress discontinuities of rock masses at two sides of the joints.

Therefore, the scope of influence of persistent joint on single-hole blasting damage of rock masses was analyzed to overcome the deficiencies in the existing studies. The prediction formulas of blasting damage scope when persistent joint passed through the upper, middle, and lower parts of the blast holes were proposed. A field blasting test was conducted on already known and relatively intact rock masses, and the blasting damage scope was acquired through the acoustic testing method. The effectiveness of the numerical calculation method was verified through the numerical calculation method combining simulation of blast load via finite element model and simulation of rock masses via discrete element software. Persistent joint under different circumstances was set through the discrete element software to investigate the scope of blasting damage zone of discontinuous rock masses and acquire the prediction formula of blasting damage scope.

The remainder of the study is organized as follows. Section 3 expounds the test design and modeling approach of numerical modeling and determination of model parameters. Section 4 verifies the effectiveness of the numerical calculation method, analyzes the scope of blasting damage zone of rock masses containing persistent joint under different circumstances, and fits the prediction formula of blasting damage scope. The final section summarizes the study and provides related conclusions.

\section{Methodology}

\subsection{Test profile}

\subsubsection{Test design and selection of blasting test site}

A field blasting test should be conducted to verify the effectiveness of numerical calculation. Finding joints with ideal classification within the scope of blast holes in the rock masses to be tested is difficult. Thus, using the pure testing method to investigate blasting damage of jointed rock masses is also complex. However, the field blasting test can be used to find relatively intact rock mass with no significant joints. This test was performed in a stone pit located in Macheng, Hubei Province, China, which had no significant persistent joint but with good intactness of rock masses. The test of field blasting damage scope was implemented through the cross-hole pitch-and-catch acoustic testing method. The basic principle of this method is to calculate the acoustic wave velocity of medium under current status according to the travel time of acoustic wave in the medium, followed by determination of rock damage scope in accordance with the stipulations specified in Construction Technical Specifications on Rock-Foundation Excavating Engineering of Hydraulic Structures(DL/T 5389-2007) [17] with regard to determination of rock damage based on change rate of acoustic wave velocity in rock masses before and after blasting. Test holes were drilled at different parts at the test site along the direction parallel to the blast holes, and acoustic wave velocity between neighboring holes in the rock masses were measured and analyzed.

\subsubsection{Mechanical property indexes of test material}

The analysis of the rock specimen acquired from the test site showed that this rock mass was mainly ignimbrite, where the main rock constituents were potassium feldspar and anorthosite, followed by quartz and hornblende, and crystal 
pyroclast, which was $0.15-1.2 \mathrm{~mm}$ in diameter (individual diameter could reach $2 \mathrm{~mm}$, mostly being within $0.3-0.8$ $\mathrm{mm}$ ) of subangular shape with uneven boundary. The main rock debris was quartzite, which was $0.3-4 \mathrm{~mm}$ in diameter of subangular shape. Following a laboratory test of basic physical and mechanical parameters, the concrete parameters of the rock material are listed in Tab. 1.

Table 1. Basic mechanical parameters of rock mass

\begin{tabular}{c|c}
\hline Parameter & Measured value \\
\hline Density $\rho / \mathrm{kg} \cdot \mathrm{m}^{-3}$ & 2677 \\
Elasticity modulus $\mathrm{E} / \mathrm{GPa}$ & 61.4 \\
Bulk modulus $\mathrm{G} / \mathrm{GPa}$ & 40.7 \\
Compressive strength $\sigma / \mathrm{MPa}$ & 208.1 \\
Poisson's ratio $\mu$ & 0.228 \\
Frictional angle $\varphi /{ }^{\circ}$ & 47 \\
Cohesive force $\mathrm{C} / \mathrm{MPa}$ & 50.3 \\
Tensile strength $\sigma_{t} / \mathrm{MPa}$ & 5.5 \\
\hline
\end{tabular}

The explosive used in the blasting was emulsion explosive dedicated for rocks; its density and blasting velocity were $1,300 \mathrm{~kg} \cdot \mathrm{m}^{-3}$ and $3,200 \mathrm{~m} \cdot \mathrm{s}^{-1}$, respectively.

\subsubsection{Test device and scheme}

The acoustic meter used in the acoustic wave velocity test in rock mass is shown in Fig. 1; its sampling interval was 0.1$6553 \mu \mathrm{s}$, sampling length was optional among $0.5,1,2,4,8$, and $16 \mathrm{~K}$, triggering level was also optional among 20, 40, $80,160,320,640,1280$, and $2500 \mathrm{mv}$, and the sampling precision could satisfy the test requirements.

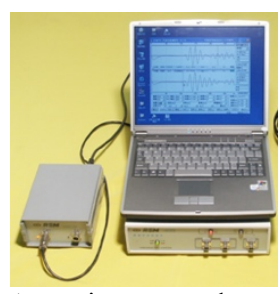

(a) Acoustic meter and computer Fig. 1. Acoustic test equipment

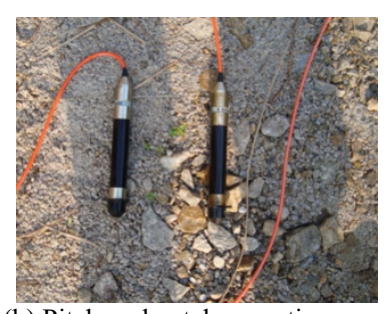

(b) Pitch-and-catch acoustic sensor
The arrangement of blast holes in the field blasting damage test of the rock mass is shown in Fig. 2; its central hole was blast hole, and 1\#-14\# holes were acoustic wave monitoring holes. The depth $\mathrm{h}_{1}$ of blast hole was $3.5 \mathrm{~m}$, hole depth $h_{2}$ in the acoustic wave test was $5.5 \mathrm{~m}$, spacing of blast holes was $\mathrm{a}=0.5 \mathrm{~m}$, the spacing between $3 \#$ and $5 \#$ holes and that between $2 \#$ and $7 \#$ holes were both $1.0 \mathrm{~m}$, and the spacing between other adjacent holes was $0.5 \mathrm{~m}$. Before the blasting, steel sleeves were placed into the monitoring holes to avoid hole collapse, which could result in testing difficulty. The emulsion explosive commonly used in engineering construction was selected, and the explosive payload was $9 \mathrm{~kg}$.

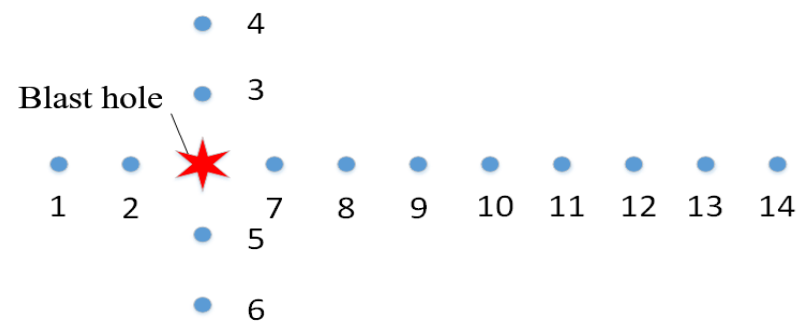

(a)
Blast hole

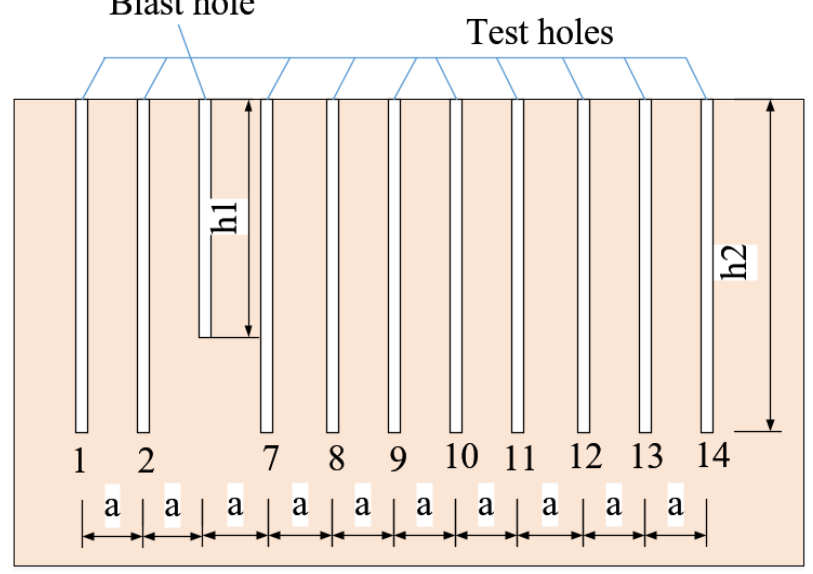

(b)

Fig. 2. Layout plan of test blast holes

\subsubsection{Measuring contents and arrangement of measuring points}

Acoustic wave velocities in $1 \#-14 \#$ holes in the rock mass before and after blasting were tested and comparatively analyzed. The depth scope of blasting damage could be acquired through the acoustic wave velocity between $3 \#$ and $5 \#$ holes, and the width scope of acoustic wave velocities between $5 \#$ and $7 \#$ holes, between $7 \#$ and $8 \#$ holes, between $8 \#$ and 9\# holes, between 9\# and 10\# holes, between 10\# and $11 \#$ holes, between $11 \#$ and 12\# holes, between 12\# and 13\# holes, and between $13 \#$ and $14 \#$ holes. The test situation is shown in the following pictures (Fig. 3).

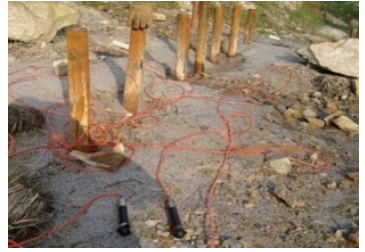

(a)

Fig. 3. Acoustic test site

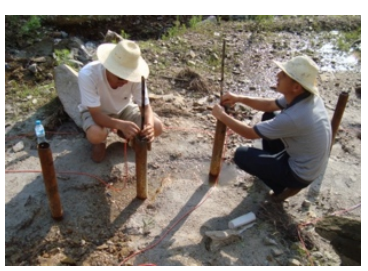

(b)

\subsection{Numerical calculation model}

\subsubsection{Calculation model of blast load}

The numerical calculation would be performed combining finite element software ANSYS/AUTODYN and discrete element software UDEC to study the blasting damage of jointed rock mass. The reason was that UDEC failed to generate dynamic load, and the blast load should be calculated via ANSYS/AUTODYN. Accordingly, the calculation model of blast load of ANSYS/AUTODYN was constructed, as shown in Fig. 4. The right side of the model was set as a symmetrical boundary, while the left side and bottom were set as nonreflecting boundaries.

Riedel-Hiermaier-Thoma constitutive calculation model [18], which is usually used to describe dynamic problems of rock and concrete materials, was selected in this model, and the concrete physical and mechanical properties are shown in Tab. 1.

Jones-Wilkens-Lee equation of states [19] was used for the explosive, and its concrete form is shown in Formula (1).

$P=A\left(1-\frac{\omega}{R_{1} V}\right) e^{-R_{1} V}+B\left(1-\frac{\omega}{R_{2} V}\right) e^{-R_{2} V}+\frac{\omega E}{V}$, 
where $\mathrm{P}$ is the blast pressure, $\mathrm{V}$ is the volume ratio of explosion products under pressure $\mathrm{P}$, and $\mathrm{E}$ is the specific internal energy of the explosive. A, B, $\mathrm{R}_{1}, \mathrm{R}_{2}$, and $\omega$ are material constants. The concrete parameter values are shown in Tab. 2.
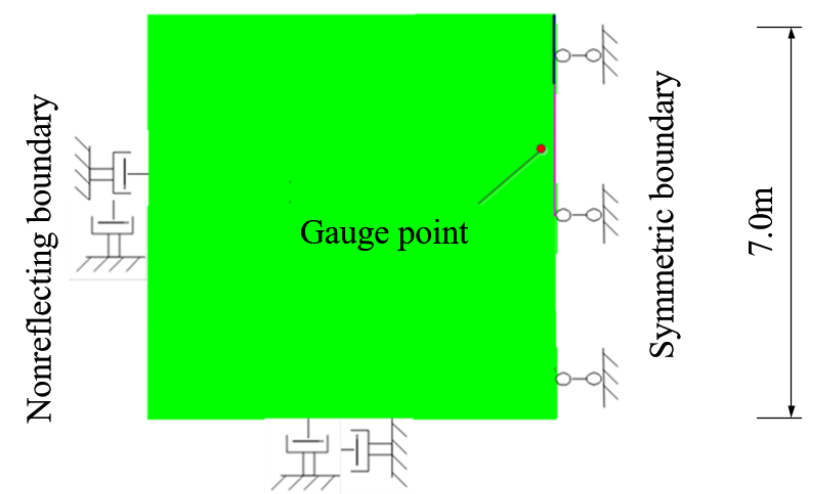

Nonreflecting boundary

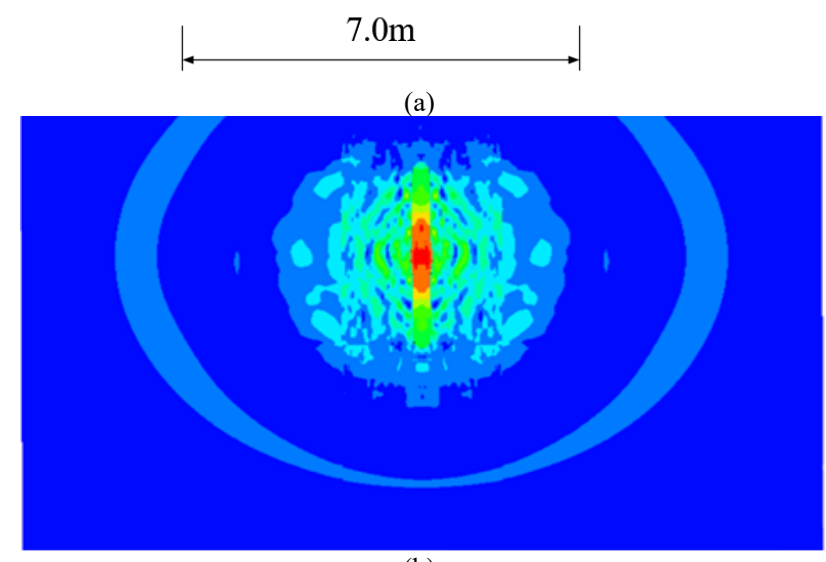

(b)

Fig. 4. Calculation model of blast load

Table 2. Basic parameters of the explosive and parameters of Jones-Wilkens-Lee state equation

\begin{tabular}{c|c}
\hline Parameter & Measured value \\
\hline Density $\rho / \mathrm{kg} \cdot \mathrm{m}^{-3}$ & 1300 \\
Blasting velocity & 3200 \\
$\mathrm{~A} / \mathrm{GPa}$ & 214.4 \\
$\mathrm{~B} / \mathrm{GPa}$ & 0.182 \\
$R_{1}$ & 4.2 \\
$R_{2}$ & 0.9 \\
$\omega$ & 0.15 \\
$E / 10^{9} \mathrm{~J} \cdot \mathrm{m}^{-3}$ & 4.192 \\
\hline
\end{tabular}

\subsubsection{Calculation model of rock damage}

In the blasting damage analysis of the established rock mass, discrete element UDEC software was used to establish models under two circumstances. The first model was used to verify the precision of UDEC in calculating blasting damage zone of the rock mass. The numerical calculation model in Fig. 5 was constructed according to test conditions at the test site. This model did not contain any persistent joint.

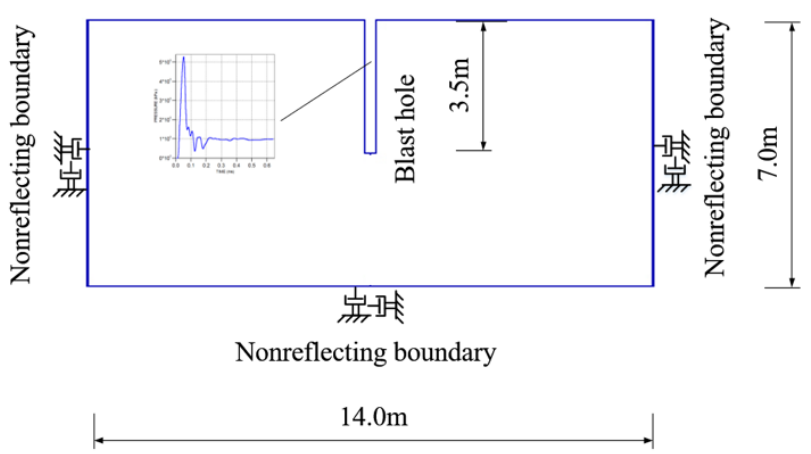

Fig. 5. Schematic of UDEC calculation model

The calculation model in which persistent joint passed through the blast hole was constructed as the second model. The joint setting is shown in Fig. 6. The joint passed through quartering points $\mathrm{P}_{1}, \mathrm{P}_{2}$, and $\mathrm{P}_{3}$ of the depth of the blast hole. The joint passing through $\mathrm{P}_{1}, \mathrm{P}_{2}$, and $\mathrm{P}_{3}$ were defined as joints I, II, and III, respectively. The angle $\alpha$ could be changed to analyze the influences of persistent joint passing through the upper, middle, and lower parts of the blast hole on the blasting damage for investigating the influence of the direction of persistent joint on the blasting damage zone. The boundary conditions used in the calculation and physical and mechanical parameters of the rock masses were the same as in the previous part.

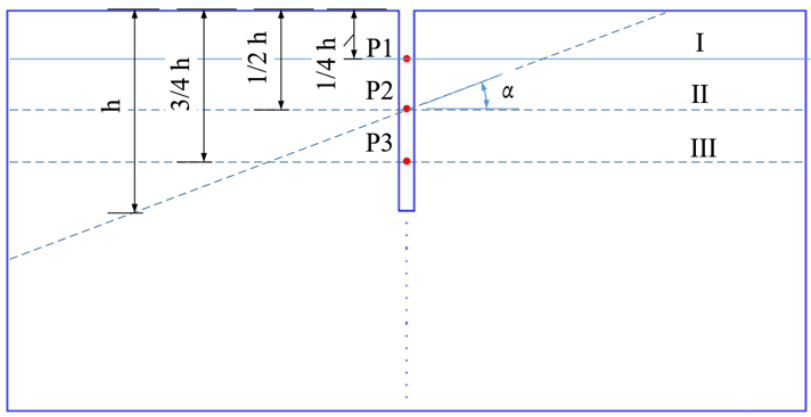

Fig. 6. Schematic of joint setting in rock masses

The constitutive model of dynamic rock damage is shown in Formula (2), where $\sigma_{f i}$ is the stress under rock fracture. $D_{f i}$ is the damage variable with a value of $0.18 . E_{i}$ is the equivalent elasticity modulus of rock mass. $\sigma_{s t i}$ is the static tensile strength in direction i. $C_{d i}$ is the crack density in direction i. $\alpha_{i}$ is calculated according to Formula (3), and $\beta_{i}$ value is taken as $2[20,21]$.

$$
\begin{gathered}
\sigma_{f i}=E_{i}\left(1-D_{f i}\right) \sigma_{s t i}+\frac{E_{i}\left(1-D_{f i}\right)}{1-2 v}\left(\frac{C_{d f i}}{\alpha_{i}}\right)^{\frac{1}{1+\beta_{i}}} \dot{\varepsilon}^{-\frac{1}{1+\beta_{i}}} \\
\alpha=\left(\frac{E\left(1-D_{f i}\right)}{\left[\sigma_{f i}-\left(1-D_{f i}\right) \sigma_{s t}\right](1-2 v)}\right)^{1+\beta} C_{d f} \dot{\varepsilon}
\end{gathered}
$$

Nonlinear Barton-Bandis (BB) model [22] was adopted to calculate joints of the rock masses. The applicability of this model to stress wave propagation has been verified in Literature [23, 24]; thus, it will not be described here in details. 
The relationship between normal stress and displacement of joints in BB model is shown in Formula (4).

$$
\sigma_{n}=\frac{-u_{n c} \cdot K_{n i}}{1-\frac{u_{n c}}{v_{m i}}},
$$

where $\sigma_{n}$ is the normal stress of joints, $u_{n c}$ is the current normal displacement of joints, $K_{n i}$ is calculated through Formula (5), and $v_{m i}$ is through Formula (6).

$$
\begin{aligned}
& K_{n i}=0.0178\left[\frac{J C S_{0}}{a_{j n}}\right]+1.748 J R C_{0}-7.155, \\
& v_{m i}=A_{i}+B_{i}\left(J R C_{0}\right)+C_{i}\left[\frac{J C S_{0}}{a_{j n}}\right]^{D_{i}},
\end{aligned}
$$

where $J C S_{0}$ is the wall compression strength of joints, $J R C_{0}$ is the roughness coefficient of joints, and $a_{j n}$ is the joint aperture. $A_{i}, B_{i}, C_{i}$, and $D_{i}$ are the calculation coefficients in the cycle $i$.

The initial joint width is calculated according to Formula (7), and the joint irrecoverable closure in each cycle can be calculated through Formula (8).

$a_{j}=\frac{J R C_{0}}{5}\left(0.2 \sigma_{c} / J C S_{0}-0.1\right)$,

$$
v_{i r r}=\left[C_{1}-C_{2}\left[\frac{J C S_{0}}{a_{j n}}\right]\right] \frac{u_{n l}}{100},
$$

where $\sigma_{c}$ is the compressive strength of rock mass, $u_{n l}$ is the maximum closure of joints, and $C_{1}$ and $C_{2}$ are the calculation coefficients.

The values of physical and mechanical parameters of the rock mass are the same as in the previous part, as shown in Tab. 1. The wall compression strength $J C S_{0}$ of joints is taken as $30 \mathrm{MPa}$, roughness coefficient $J R C_{0}$ is 8 , maximum permitted closure $u_{n l}$ is $1 \mathrm{~mm}$, initial normal stiffness and tangential stiffness are $40 \mathrm{GPa}$, and the values of $A_{i}, B_{i}, C_{i}$, $D_{i}, C_{1}$, and $C_{2}$ are shown in Tab. 3 .

Table 3. Calculation coefficients

\begin{tabular}{c|c|c|c|c}
\hline Cycle & 1 & 2 & 3 & 4 \\
\hline$A_{i}$ & -0.296 & -0.1005 & -0.1031 & -0.1031 \\
$B_{i}$ & -0.0056 & -0.0073 & -0.0074 & -0.0074 \\
$C_{i}$ & 2.241 & 1.0082 & 1.135 & 1.135 \\
$D_{i}$ & -0.245 & -0.230 & -0.251 & -0.251 \\
$C_{1}$ & 84.77 & 44.37 & 31.38 & 20 \\
$C_{2}$ & 0.02 & 0.01 & 0.01 & 0.01 \\
\hline
\end{tabular}

\section{Test results and analysis}

\subsection{Field blasting test results}

The stipulations specified in China Construction Technical Specifications on Rock-Foundation Excavating Engineering of Hydraulic Structures(DL/T 5389-2007) [17] indicated that, when the change rate of acoustic wave velocity in the rock mass before and after blasting is $\eta=1-\left(C / C_{0}\right) \leq 10 \%$, the rock mass can be considered not influenced. Thus, $\frac{C}{C_{0}}=0.9$ can be the threshold of rock blasting damage. This value was taken as the threshold damage in the field test to judge blasting damage of the rock mass.

Following the standard that the change rate of acoustic wave velocity should be $\eta>10 \%$, the blasting damage depth could be acquired by testing the change rates of acoustic wave velocities in $3 \#-5 \#$ holes and $2 \#-7 \#$ holes. Blasting damage radius could be acquired by testing the change rates of acoustic wave velocity in $3 \#-7 \#, 7 \#-8 \#, 8 \#$ $9 \#, 9 \#-10 \#, 10 \#-11 \#, 11 \#-12 \#, 12 \#-13 \#$, and $13 \#-14 \#$ holes. The concrete results after the acoustic test are shown in Fig. 7, where the damage radius is $3.25 \mathrm{~m}$ and the damage depth is $1.03 \mathrm{~m}$.

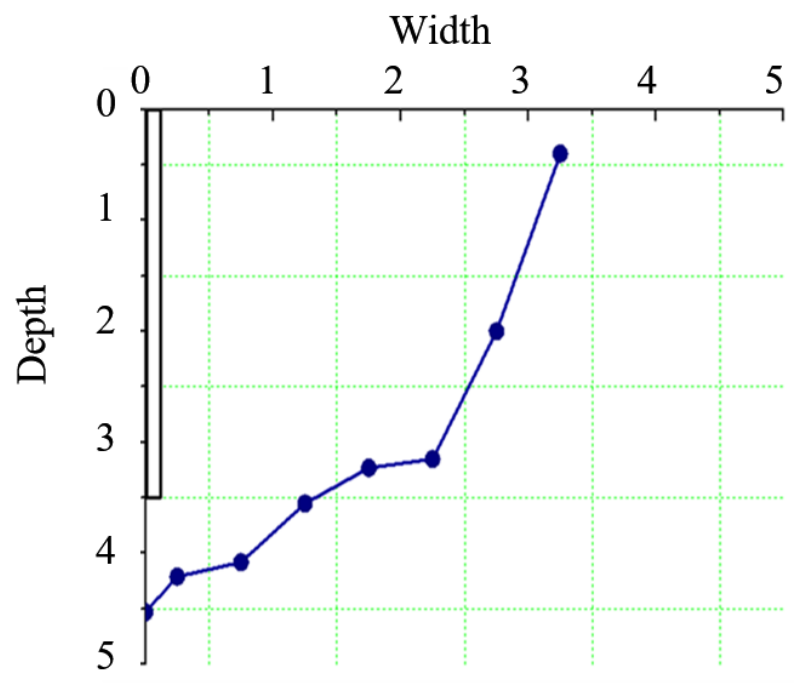

Fig. 7. Scope of rock blasting damage

\subsection{Verification through numerical calculation}

4.2.1 Verification of calculation result of blast load through ANSYS/AUTODYN

Dai [25] indicated that the radius of rock crushing zone induced by column blasting was three times the charging radius. Given that the emphasis in this study was laid on rock damage, the boundary of crushing zone was taken as the boundary of UDEC software, where the load was applied. The measuring points of the corresponding blasting pressure were arranged, as shown in Fig. 3. After the calculation through ANSYS/AUTODYN, the peak blasting pressure at the edge of the crushing zone could be known as $529 \mathrm{MPa}$ (Fig. 8).

The study results of Literature [25] showed that, under coupling charging conditions, the initial maximum detonation pressure in the blast hole is

$p_{d}=\frac{\rho_{0} D^{2}}{\gamma+1} \times \frac{2 \rho_{\mathrm{m}} c_{\mathrm{p}}}{\rho_{0} D+\rho_{\mathrm{m}} c_{\mathrm{p}}}$, 
where $\rho_{0}$ is the charging density, $\mathrm{D}$ is the blasting velocity, $\rho_{\mathrm{m}}$ is the material density, $\gamma$ is the adiabatic exponent with a value of 3 , and $c_{\mathrm{p}}$ is the $\mathrm{P}$-wave velocity of material. The attenuation law of peak blasting stress wave $P_{r}$ in rock mass with distance $r$ is presented as

$$
P_{r}=\sigma_{r \mathrm{~d}}=p_{d}\left(\frac{a}{r}\right)^{\alpha}
$$

where a is the radius of blast hole and $\alpha$ is the attenuation index of stress wave. $\alpha=2-\frac{\mu_{d}}{1-\mu_{d}}$, where $\mu_{d}$ is the dynamic Poisson's ratio of rock with a value of $\mu_{d}=0.8 \mu$.

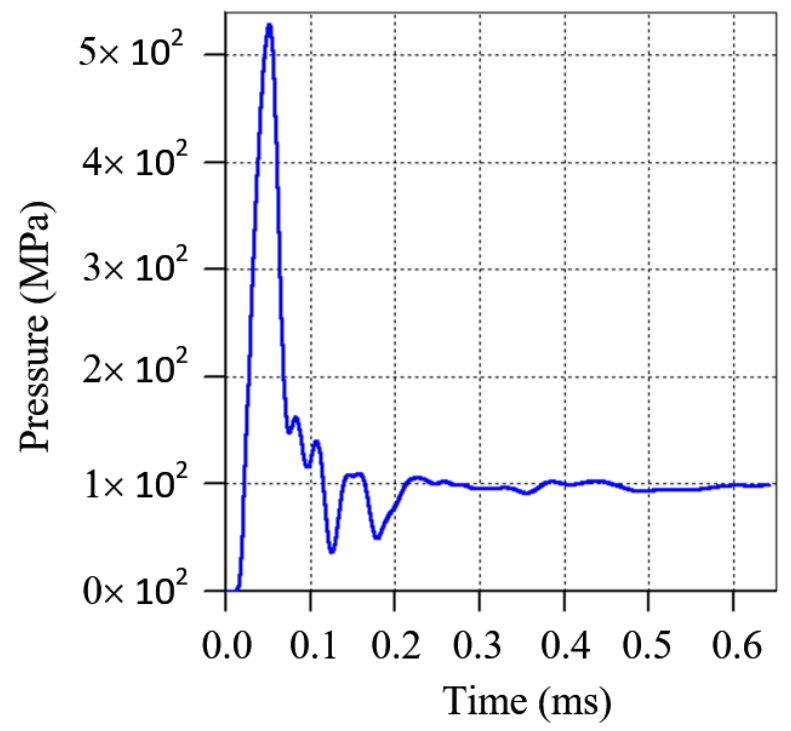

Fig. 8. Pressure time-history curve of measuring points at boundary of breakage zone

The calculation was implemented according to the abovementioned theory. The peak blasting pressure at the boundary of crushing zone was $P_{r}=636.7 \mathrm{MPa}$. Theories and tests regarding calculation of blasting pressure nearby the blast hole are few. Thus, obtaining an exact solution is difficult. The previous analysis shows that the numerical calculation result is approximate to the theoretical calculation result; thus, it can reflect the impact load characteristics at the boundary of the blasting-induced crushing zone and can satisfy the requirement for calculation accuracy. This load will be used as input load for discrete element UDEC software in the follow-up analysis.

\subsubsection{Verification of calculation results of blasting} damage zone in intact rock mass through UDEC

The constitutive model of damage used by UDEC software to calculate blasting damage zone of intact rock mass is shown in Formula (2). The basic physical and mechanical parameters of the rock mass are the same as those listed in Tab. 1. The blasting damage zone of the rock mass can be calculated as shown in Fig. 9. The statistical results show that the damage radius and depth are 3.4 and $1.1 \mathrm{~m}$, respectively, which are consistent with the field test results. Therefore, the numerical calculation is effective and reliable.

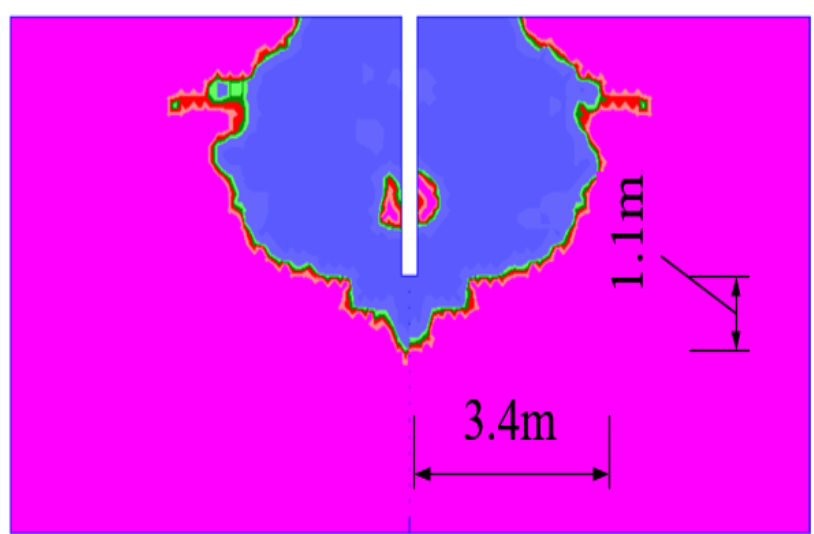

Fig. 9. Blasting damage zone of rock mass calculated through UDEC

\subsection{Influence analysis of persistent joint on blasting} damage zone

The calculation model applied to influence analysis of persistent joint on blasting damage zone is shown in Fig. 6. For example, when joint I passed through upper part of the blast hole, angle $\alpha$ was regulated as $0^{\circ}, 15^{\circ}, 30^{\circ}, 45^{\circ}, 60^{\circ}$, and $75^{\circ}$, and the propagation process of blasting stress wave in the jointed rock masses could be acquired. The blasting stress wave propagation under the joint angle of $45^{\circ}$ is shown in Fig. 10. The figure shows that, after the stress waves encountered joints, the stress waves nearby the blast hole with high frequency were all reflected at the joint position because of the high-frequency filter action of the joint. As a result, the stress wave propagation in the jointed rock masses presented a discontinuous characteristic.

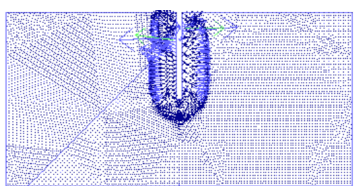

(a)

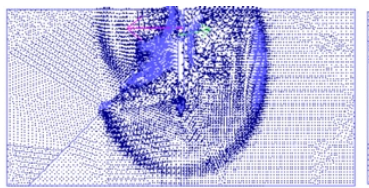

(c)

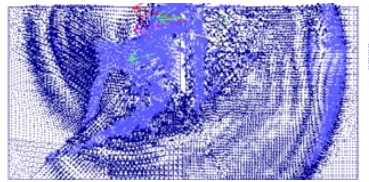

(e)

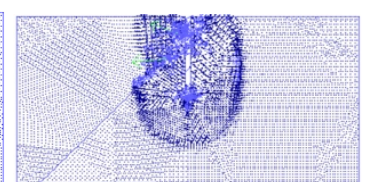

(b)

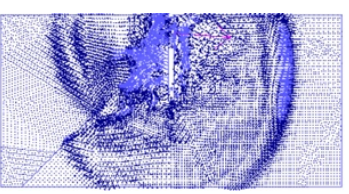

(d)

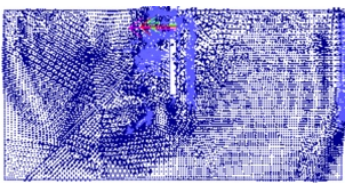

(f)
Fig. 10. Schematic of blasting stress wave propagation

The distribution of blasting damage zones, which was similar to stress wave propagation, showed very significant discontinuity because of the existence of joint. The calculation results of the blasting damage zones under different working conditions are shown in Figs. 11-13. 
Bing Xie, Yanqiang Du, Hongling Zhao, Zhigang Du and Brian Mullarney/

Journal of Engineering Science and Technology Review 13 (3) (2020) 42 - 51

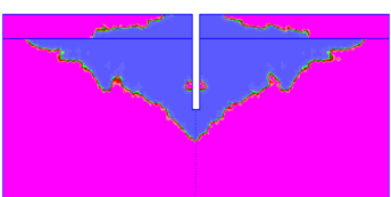

(a) $0^{\circ}$

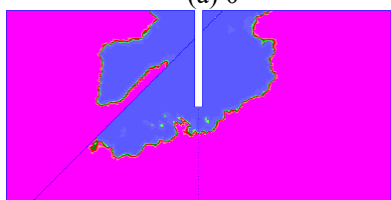

(d) $45^{\circ}$

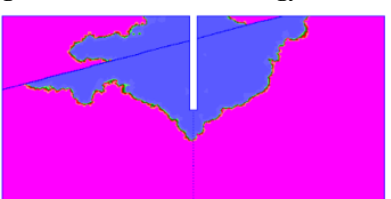

(b) $15^{\circ}$

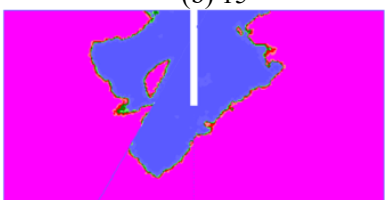

(e) $60^{\circ}$

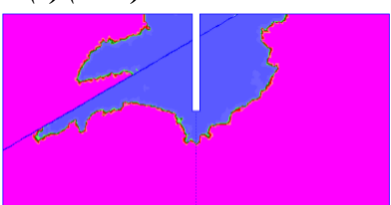

(c) $30^{\circ}$

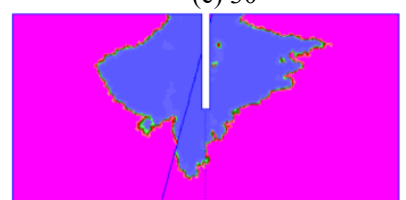

(f) $75^{\circ}$

Fig. 11. Distribution of rock damage zones under different angles of joint I

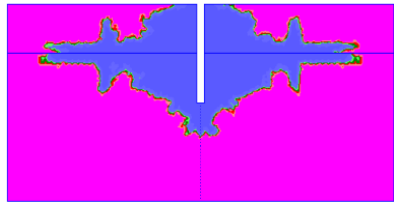

(a) $0^{\circ}$

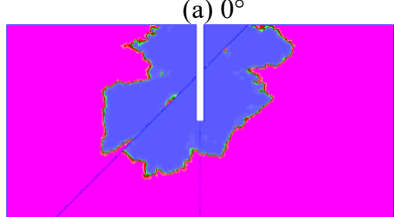

(d) $45^{\circ}$

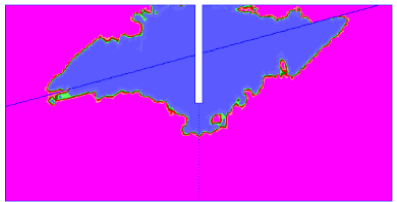

(b) $15^{\circ}$

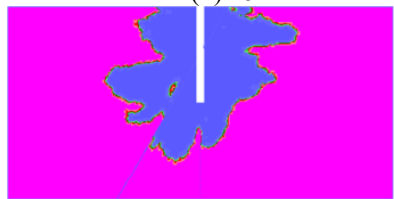

(e) $60^{\circ}$

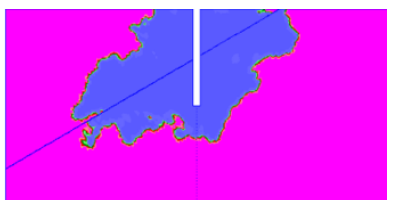

(c) $30^{\circ}$

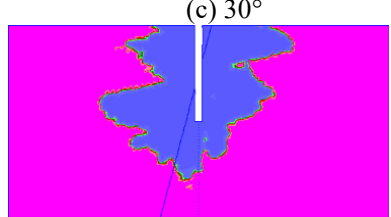

(f) $75^{\circ}$

Fig. 12. Distribution of rock damage zones under different angles of joint II
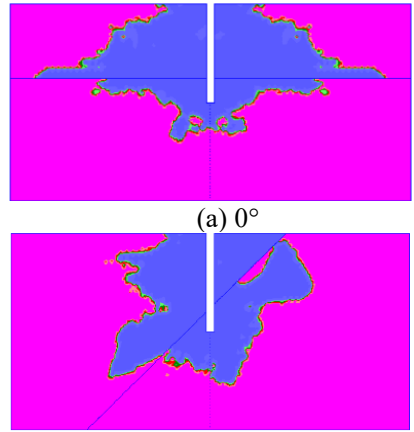

(d) $45^{\circ}$

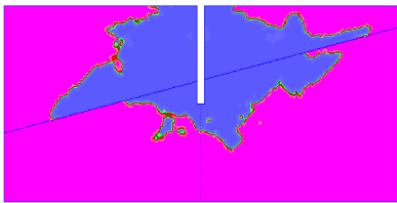

(b) $15^{\circ}$

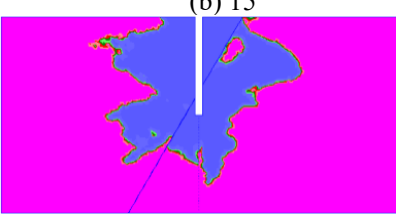

(e) $60^{\circ}$

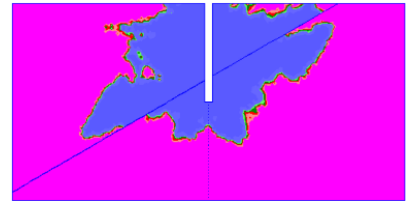

(c) $30^{\circ}$

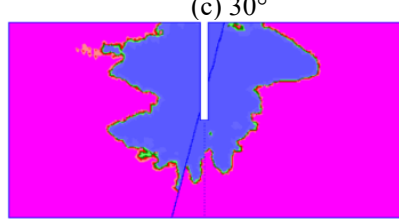

(f) $75^{\circ}$

Fig. 13. Distribution of rock damage zones under different angles of joint III

The calculation results showed that, when the joint passed through the upper part of the blast hole, the scope of horizontal rock blasting damage under the joint dip angles of $0^{\circ}, 15^{\circ}$, and $30^{\circ}$ was obviously enlarged relative to the circumstance of non-jointed rock mass. However, the vertical damage depth presented no obvious change. Under the dip angles of $45^{\circ}, 60^{\circ}$, and $75^{\circ}$, the scope of horizontal rock blasting damage presented no significant change relative to the circumstance of non-jointed rock mass. However, the vertical damage depth was obviously increased. In addition, the rock damage scope below the joint was larger than that above the joint under a small joint dip angle. This phenomenon was due to that, when the joint passed through the upper part of the blast hole, more stress waves below the blast hole were propagated to the joint and interacted with the joint after blasting. Accordingly, reflective stretching and rock failure occurred. This phenomenon could be observed from the stress wave propagation process in Fig. 9. The similar phenomenon was also manifested when the joint passed through the middle or lower part of the blast hole relative to non-joint condition. The scope of horizontal rock blasting damage was enlarged under a small joint dip angle, but the vertical damage depth changed slightly. Under a large joint dip angle, the scope of horizontal rock blasting damage underwent no significant change, while the vertical damage depth was obviously increased. The statistical results of blasting damage scope caused by different conditions of persistent joint are listed in Table 4.

If the ratios of damage width and depth to the corresponding values under non-joint condition are defined as proportionality coefficients of blasting damage and taken as the $\mathrm{x}$-coordinate and joint dip angle is taken as $\mathrm{y}$ coordinate, then the change laws of blasting damage zones when persistent joint passes through the upper, middle, and lower parts of the blast hole relative to non-joint conditions can be acquired as shown in Fig. 14.

Figure 14 shows that the existence of joints will significantly influence the distribution range of rock blasting damage zone. When persistent joint passed through the upper part of the blast hole and the joint dip angle changed within $0^{\circ}-75^{\circ}$, the maximum rock damage width and maximum damage depth were 1.81 and 2.31 times those under non-joint condition, respectively. Similarly, when the joint passed through the middle part of the blast hole, the maximum damage width and maximum damage depth were 1.69 and 1.97 times those under non-joint condition. When the joint passed through the lower part of the blast hole, the maximum damage width and maximum damage depth were 1.83 and 2.28 times those under non-joint condition. The 
prediction formula of blasting damage scope of persistently jointed rock mass was established by fitting of data scatters. The expressions of change laws of proportionality coefficient of its damage width are shown in Formulas (11),
(12), and (13), and those of its damage depth are shown in Formula (14), (15), and (16).

Table 4. Statistical table of damage scope of rock mass under different joint conditions

\begin{tabular}{|c|c|c|c|c|c|c|c|}
\hline \multirow{3}{*}{ Model type } & \multirow{3}{*}{ Parameters } & \multicolumn{6}{|c|}{ Computed results } \\
\hline & & \multicolumn{6}{|c|}{ Joint dip angle $\alpha /^{\circ}$} \\
\hline & & 0 & 15 & 30 & 45 & 60 & 75 \\
\hline \multirow{4}{*}{ Joint I } & Damage width $\mathrm{Lh} / \mathrm{m}$ & 6.16 & 6.11 & 5.81 & 3.92 & 3.68 & 4.21 \\
\hline & Proportionality coefficient of damage width & 1.81 & 1.8 & 1.71 & 1.15 & 1.08 & 1.24 \\
\hline & Damage depth Lv/m & 1.16 & 1.14 & 1.21 & 1.80 & 2.53 & 2.54 \\
\hline & Proportionality coefficient of damage depth & 1.05 & 1.04 & 1.1 & 1.64 & 2.3 & 2.31 \\
\hline \multirow{4}{*}{ Joint II } & Damage width $\mathrm{Lh} / \mathrm{m}$ & 5.76 & 5.48 & 4.57 & 3.64 & 3.57 & 3.63 \\
\hline & Proportionality coefficient of damage width & 1.69 & 1.61 & 1.34 & 1.07 & 1.05 & 1.07 \\
\hline & Damage depth Lv/m & 1.19 & 1.19 & 1.37 & 2.03 & 2.13 & 2.17 \\
\hline & Proportionality coefficient of damage depth & 1.08 & 1.08 & 1.25 & 1.85 & 1.94 & 1.97 \\
\hline \multirow{4}{*}{ Joint III } & Damage width $\mathrm{Lh} / \mathrm{m}$ & 6.21 & 6.1 & 4.57 & 3.61 & 3.87 & 4.11 \\
\hline & Proportionality coefficient of damage width & 1.83 & 1.79 & 1.34 & 1.06 & 1.14 & 1.21 \\
\hline & Damage depth Lv/m & 1.54 & 1.61 & 1.59 & 1.9 & 2.49 & 2.51 \\
\hline & Proportionality coefficient of damage depth & 1.41 & 1.46 & 1.45 & 1.73 & 2.26 & 2.28 \\
\hline
\end{tabular}

$K_{\mathrm{hI}}=1.81-0.79 e^{\left(-e^{(51.6 \times x / 18.36)}+\frac{56.31-x}{18.36}+1\right)}$

$K_{\mathrm{hI}}=1.71-0.69 e^{\left(-e^{(58.98-x / 30.47)}+\frac{58.98-x}{30.47}+1\right)}$

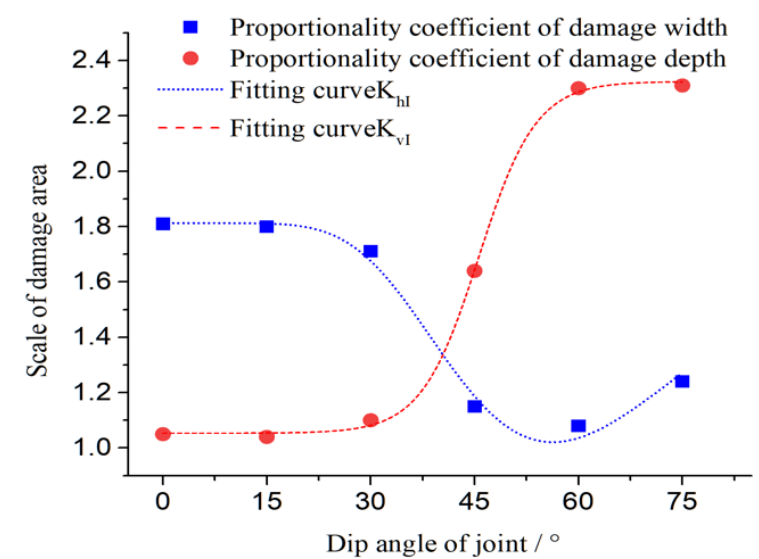

(a) Conditions of joint I

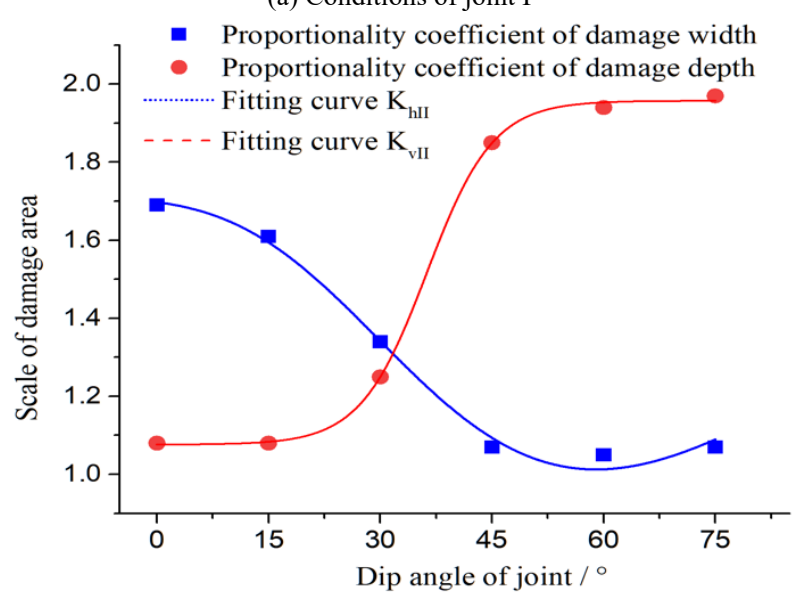

(b) Conditions of joint II

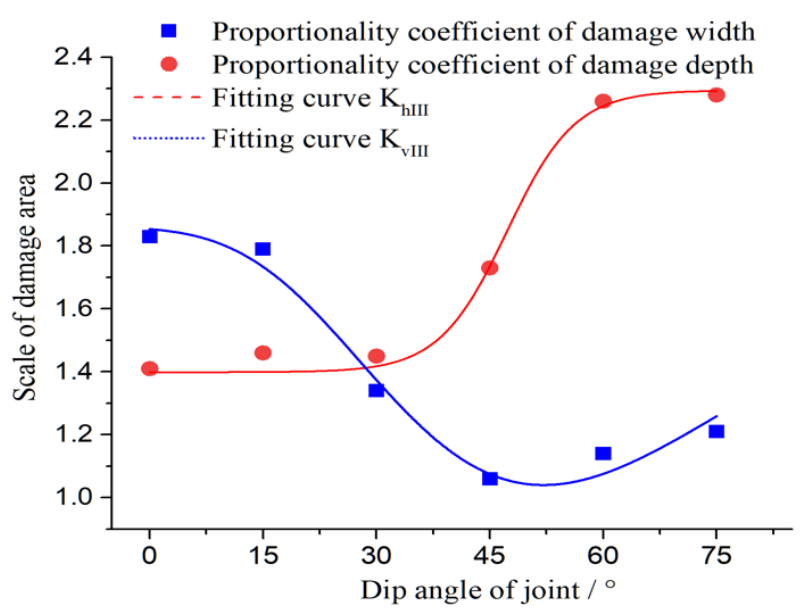

(c) Conditions of joint III

Fig. 14. Change laws of damage zone in jointed rock mass relative to non-jointed rock mass

$K_{\mathrm{hI}}=1.86-0.82 e^{\left(-e^{(52.09 \cdot x / 25.28)}+\frac{52.09-x}{25.28}+1\right)}$

$K_{v I}=-\frac{1.27}{1+e^{(x-45.59) / 4.14}}+2.32$

$K_{v I I}=-\frac{0.88}{1+e^{(x-36.25) / 4.45}}+1.96$

$K_{v I I I}=-\frac{0.89}{1+e^{(x-47.27) / 4.5}}+2.29$

\subsection{Discussion of special circumstance}

When a joint simultaneously passed through $\mathrm{P}_{1}, \mathrm{P}_{2}$, and $\mathrm{P}_{3}$, this joint was overlapped with axis of the blast hole under the joint dip angle of $90^{\circ}$. The calculation showed that the width and depth of blasting damage zone were 3.41 and 2.48 $\mathrm{m}$, respectively, which were 1 and 2.25 times those under non-joint condition, as shown in Fig. 15. The distribution of damage zones indicated that the damage width under the joint dip angle of $90^{\circ}$ was consistent with the blasting damage width of the non-jointed rock mass. The joint was located at the bottom of the blast hole and overlapped with 
the axis of the blast hole. The blasting stress at the side wall of the blast hole would be freely propagated along the width direction and would not interact with the joint. Thus, the change of blasting damage width would not be influenced. Stress waves under oblique incidence would interact with the joint along the depth direction. Thus, reflective stretching and rock damage near the joint occurred, and the damage would gradually develop along the joint. Thus, the damage depth was evidently larger than that of non-jointed rock mass.

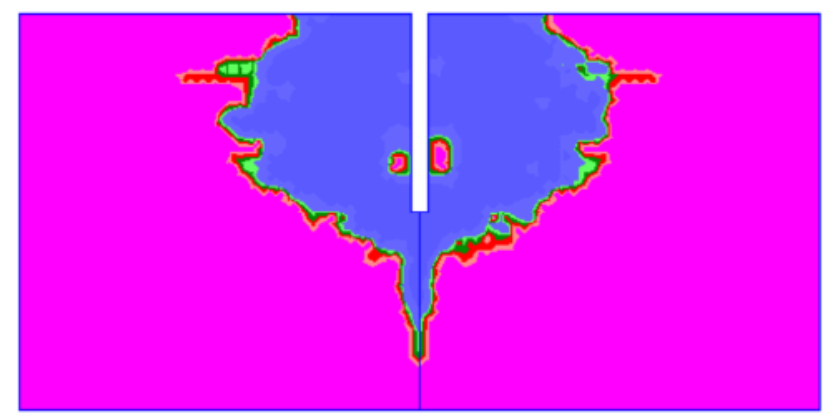

Fig. 15. Damage zone distribution in rock mass under the joint dip angle of $90^{\circ}$

\section{Conclusions}

The blasting damage zone of a rock mass was analyzed in this study through a field test to acquire the influence laws of persistent joint on blasting damage zone of engineering rock masses. The blasting damage zones formed when persistent joint passed through the blast hole were analyzed through the calculation method combining finite element ANSYS/AUTODYN software and discrete element UDEC software. The following conclusions were drawn:

(1) The scope of blasting damage zone in the rock mass not containing persistent joint was determined through the field blasting test, followed by rechecking and verification via UDEC software. The calculation results indicated that the UDEC-assisted calculation result of blasting damage was accurate and could meet the requirement for calculation accuracy of blasting damage.

(2) The typical numerical models of joints passing through the upper, middle, and lower parts of the blast hole were built, and the distribution laws of blasting damage zones in the rock mass under the joint dip angles of $0^{\circ}, 15^{\circ}, 30^{\circ}, 45^{\circ}$, $60^{\circ}$, and $75^{\circ}$ were investigated. The existence of persistent joint would remarkably influence the distribution pattern of blasting damage zones. Whether the joint passed through the upper, middle, or lower parts of the blast hole, the joint could greatly influence the blasting damage width under a small joint dip angle. The maximum damage width was approximately 1.8 times that under non-joint condition. Under a large dip angle, the joints could influence the blasting damage depth to a great degree. The damage depth was nearly 2.3 times that under non-joint condition and presented nonlinear laws with consistent tendencies.

(3) Under the special circumstance in which the joint with the dip angle of $90^{\circ}$ was overlapped with axis of the blast hole, the joint had no influence on blasting damage width but exerted a prominent effect on damage depth. The scope of influence was approximate to that under large joint dip angle $\left(75^{\circ}\right)$.

The influence laws of persistent joint on blasting damage zone of rock mass were explored by combining field test and numerical calculation. Macroscopic morphological characteristics of blasting damage zone when persistent joint passed through the upper, middle, and lower parts of the blast hole were acquired. The prediction formulas regarding the influences of persistent joint on blasting damage width and damage depth were acquired to provide a reference for design, construction, and reinforcement of blasting engineering. However, other influencing factors of deeply buried rock are unpredictable because of the great complexity of engineering rock masses, and the influence of complex joint conditions on blasting damage zone in rock masses remains to be further explored in the follow-up study.

\section{Acknowledgements}

This work was supported financially by the project of the Science and Technology Department of Henan Province of China (202102310570, 202102310612, 182102310730), as well as the Education Department of Henan Province of China (20A440008).

This is an Open Access article distributed under the terms of the Creative Commons Attribution License

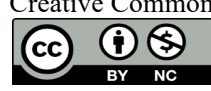

\section{References}

1. Taylor, L. M., Chen, E.Kuszmaul, J. S., "Microcrack-induced damage accumulation in brittle rock under dynamic loading". Computer Methods in Applied Mechanics and Engineering, 55(3), 1986, pp.301-320.

2. Yang, R., Bawden, W. F.Katsabanis, P. D., "A new constitutive model for blast damage". International Journal of Rock Mechanics and Mining Sciences \& Geomechanics Abstracts, 33(3), 1996, pp.245-254.

3. Xie, L. X., Lu, W. B., Zhang, Q. B., Jiang, Q. H., Wang, G. H.Zhao, J., "Damage evolution mechanisms of rock in deep tunnels induced by cut blasting". Tunnelling and Underground Space Technology, 58, 2016, pp.257-270.

4. Yang, J., Lu, W., Hu, Y., Chen, M.Yan, P., "Numerical simulation of rock mass damage evolution during deep-buried tunnel excavation by drill and blast". Rock Mechanics and Rock Engineering, 48(5), 2015, pp.2045-2059.
5. Liu, H. Y., Lv, S. R., Zhang, L. M.Yuan, X. P., "A dynamic damage constitutive model for a rock mass with persistent joints". International Journal of Rock Mechanics and Mining Sciences, 75, 2015, pp.132-139.

6. Pramanik, R.Deb, D., "Implementation of Smoothed Particle Hydrodynamics for Detonation of Explosive with Application to Rock Fragmentation". Rock Mechanics and Rock Engineering, 48(4), 2015, pp.1683-1698.

7. Dehghan Banadaki, M. M.Mohanty, B., "Numerical simulation of stress wave induced fractures in rock". International Journal of Impact Engineering, 40-41, 2012, pp.16-25.

8. Bendezu, M., Romanel, C.Roehl, D., "Finite element analysis of blast-induced fracture propagation in hard rocks". Computers \& Structures, 182, 2017, pp.1-13.

9. Liu, H. Y.Su, T. M., "A dynamic damage constitutive model for a rock mass with non-persistent joints under uniaxial compression". Mechanics Research Communications, 77, 2016, pp.12-20. 
Bing Xie, Yanqiang Du, Hongling Zhao, Zhigang Du and Brian Mullarney/

Journal of Engineering Science and Technology Review 13 (3) (2020) 42 - 51

10. Hamdi, E., Romdhane, N. B.Le Cléac H, J. M., "A tensile damage model for rocks: Application to blast induced damage assessment". Computers and Geotechnics, 38(2), 2011, pp.133-141.

11. Maxwell, S. C.Young, R. P., "Seismic imaging of blast damage". International Journal of Rock Mechanics and Mining Sciences \& Geomechanics Abstracts, 30(7), 1993, pp.1435-1440.

12. Verma, H. K.Prasad, V., "Blast induced damage to surrounding rock mass in an underground excavation". Journal of Geological Resource and Engineering, 2, 2014, pp.13-19.

13. Navarro, J., Sanchidrián, J. A., Segarra, P., Castedo, R., Costamagna, E.López, L. M., "Detection of potential overbreak zones in tunnel blasting from MWD data". Tunnelling and Underground Space Technology, 82, 2018, pp.504-516.

14. Yilmaz, O.Unlu, T., "Three dimensional numerical rock damage analysis under blasting load". Tunnelling and Underground Space Technology, 38, 2013, pp.266-278.

15. García Bastante, F., Alejano, L.González-Cao, J., "Predicting the extent of blast-induced damage in rock masses". International Journal of Rock Mechanics and Mining Sciences, 56, 2012, pp.4453

16. Jayasinghe, L. B., Shang, J., Zhao, Z.Goh, A., "Numerical investigation into the blasting-induced damage characteristics of rocks considering the role of in-situ stresses and discontinuity persistence". Computers and Geotechnics, 116, 2019, pp.103207.

17. China, Ministry of Water Resources, Construction technical specifications on rock-foundation excavating engineering of hydraulic structures (DLT5389-2007). China Water Power Press, Beijing (in Chinese) , 2007, pp.
8. Riedel, W., Wicklein, M.Thoma, K., "Shock properties of conventional and high strength concrete: Experimental and mesomechanical analysis". International Journal of Impact Engineering, 35(3), 2008, pp.155-171.

19. Castedo, R., Natale, M., López, L. M., Sanchidrián, J. A., Santos, A. P., Navarro, J.Segarra, P., "Estimation of Jones-Wilkins-Lee parameters of emulsion explosives using cylinder tests and their numerical validation". International Journal of Rock Mechanics and Mining Sciences, 112, 2018, pp.290-301.

20. Liu, L.Katsabanis, P. D., "Development of a continuum damage model for blasting analysis". International Journal of Rock Mechanics and Mining Sciences, 34(2), 1997, pp.217-231.

21. Ma, G. W., Hao, H.Wang, F., "Simulations of explosion-induced damage to underground rock chambers". Journal of Rock Mechanics and Geotechnical Engineering, 3(1), 2011, pp.19-29.

22. Bandis, S. C., Lumsden, A. C.Barton, N. R., "Fundamentals of rock joint deformation". International Journal of Rock Mechanics and Mining Sciences \& Geomechanics Abstracts, 20(6), 1983, pp.249-268.

23. Fan, L. F., Ma, G. W.Li, J. C., "Nonlinear viscoelastic medium equivalence for stress wave propagation in a jointed rock mass". International Journal of Rock Mechanics and Mining Sciences, 50, 2012, pp.11-18.

24. Li, J. C.Ma, G. W., "Experimental study of stress wave propagation across a filled rock joint”. International Journal of Rock Mechanics and Mining Sciences, 46(3), 2009, pp.471-478.

25. Dai, J., "Calculation of Radii of the Broken and Cracked Area in Rock by a Long Charge Explosion". Journal of Liaoning Technical University(Natural Science) (in Chinese), 20(2), 2001, pp.144-147. 